\title{
Research on the competency model of chancellors in charge of scientific research in Chinese research-oriented universities
}

\author{
Wei Hu, Kun Ding, Li Gu, Zhao Qu* \\ School of Public Administration and Law, Institute of Science Studies and S and T Management, WISE Lab, Dalian University of Technology,
} Dalian 116024, China

\begin{abstract}
This paper targets at competency of the chancellors in charge of scientific research in Chinese research-oriented universities, and makes in-depth researches by key behavioral event interview method and multivariate statistical analysis method. Basing on 473 valid questionnaires as collected from 28 research-oriented universities nation-wide, the competency model of the chancellors in charge of scientific research in Chinese research-oriented universities is established with exploratory factor analysis and confirmatory factor analysis methods. It is shown from the results the aforesaid competency is composed of 10 competency characteristics, which are covered by four major dimensions: Ideological and political qualities, personal qualities, business skills, and professional skills.
\end{abstract}

Keywords: Chancellors in charge of scientific research, competency, research-oriented universities, structural equation modeling

\section{INTRODUCTION}

Under the trend of globalization, research-oriented universities have become the center of national scientific research, and played a leading role in development of innovative countries. As the executive head of research-oriented university, chancellor is regarded as the soul of the university; there are underlying causes why a college or university maintains its competitive advantage, and chancellor is an extremely important factor. As a university chancellor, successful management on university is indeed just as implementation of larger research project where tens of thousands of individuals strive for the same

*Address for correspondence:

E-mail: qz_31@sina.cn

\begin{tabular}{|l|l|}
\hline \multicolumn{2}{|c|}{ Access this article online } \\
\hline Quick Response Code: & Website: \\
\hline & www.jscires.org \\
\cline { 2 - 3 } & \\
\hline
\end{tabular}

given goal, by utilizing conditions and investment supplied by the country, thus to meet the needs of countrymen. ${ }^{[1]}$ As said by Derek Bok, the American higher education expert, former chancellor of Harvard University, "whether the chancellor plays an effective leadership role is very critical to an university's success and progress in the face of multiple challenges of modern society." Great country needs a batch of high level research-oriented universities, and high-level research-oriented universities also need such the chancellors characterized by outstanding qualities and ability.

\section{Background of the Research}

Over recent years, some scholars have focused on research on competency of domestic university chancellors and their descriptive studies account for a larger proportion. ${ }^{[2-5]} \mathrm{Li}^{[6]}$ sums up 64 competency indicators of senior managers from universities through extensive literature research, and then he implements behavioral event interview (BEI) to senior managers, to further screen, merge, correct and complement, finally concludes 39 indicators of competency. Then the questionnaires and multivariate 
statistical methods (factor analysis and chancellor component analysis) are adopted to work out the final 11 competency common factors, and these factors are interpreted and weight-calculated.

Basing on the above, a university senior manager competency model is established. The 11 common factors include academic research ability (expertise, research skills, learning ability and academic exchange ability), team management and leadership skills (organization and coordination, use of personal, training ability, team-building ability, motivation and command ability, team-working consciousness and training assistance and authorization), humane care (service awareness, pleasant personality, humane care and affinity), flexibility (expected response ability, pressure bearing ability and crisis management ability), loyalty and dedication (high sense of responsibility and mission, dedication, self-control and dedication ability), analytic thinking (ability to make decisions, observing the thinking ability, political insight and information collection and analysis ability), public relations skills (social skills and financing ability), personal basic quality (rich life experience, time management skills and humanities), interpersonal expression (language expression skills, writing skills, interpersonal skills and communication skills), system thinking (strategic planning ability and overall awareness) and innovation (independent innovation capability inspiration and active inspiration).

$\mathrm{Ma}^{[7]}$ proposes a leadership system for university chancellors composed of four dimensions and 8 specific abilities, by combining the research literature related to leadership, basing on the specific circumstances of university chancellors. Then through BEI, expert consultation and individual chancellors testing, he prepares and revises the questionnaire; selects senior managers from some colleges and universities in Guangdong Province and Anhui Province to participate in survey questionnaire. He further amends questionnaire and makes exploratory analysis on the survey results, thus verifying the leadership system. The leadership system contains foresight (responsibility and thinking), execution ability (communication skills and understanding skills), cultivating ability (moral ability and emotional ability) and development ability (adaption and planning ability). Targeting at competency of chancellors in Chinese universities, Liu et al..$^{[8]}$ makes exploratory factor analysis and confirmatory factor analysis to conclude competency structure model of university chancellors, through interviews on key events and questionnaires to 32 colleges and universities nation-wide directly attached to the Ministry of Education. The study results show that the competency of university chancellors contains charisma (open-mind, psychology, motivation, passion and physical quality), educational philosophy (foresight thinking on education, clear educational philosophy, political sensitivity and social responsibility), management ability (ability to execute, teaching team building, learning ability, positioning ability and scientific decision-making ability), interpersonal ability (resource integration, ability to determine critical interests, communication skills, social skills and team-building skills) and development consciousness (academic prestige, strategic planning, innovation ability and vision capability). The research group (2010) ${ }^{[9]}$ of "research on comprehensive appraisal system reflecting the scientific concept of development on top officers from colleges and universities" implements key event interview to 28 top officers from colleges and universities under "985" and " 211 " programs, encodes interview contents in combination with internationally common "competency dictionary" and rigorous coding procedures; then it makes detailed statistical analysis on the encoding results, thus builds a leadership competency model for top officers from colleges and universities. The model is composed of thinking, leadership, influence, ambition as well as supplementary five competency groups. Among them, the leadership group includes training for others, teamwork and team leadership; thinking group includes analytical thinking and flexibility. The influence group includes impact effect and organizational identity; ambition group includes initiative and achievement orientation. And the new supplementary competency includes innovation, charisma, courage and forward thinking.

\section{Summary of Competencies}

Research on competencies can be traced back to the research on "scientific management" by Taylor as known as "the father of scientific management", which is also named as "management competencies movement". In 1911, he found there was difference in completion time between excellent workers and incompetent workers, thus he proposed that managers use time and motion analysis method to define competency structure of workers; he also proposed to improve workers' competencies through systemic training or development activities, thus improving organizational effectiveness. In 1959, the concept Competency was proposed by Robert White. Then McClelland, Harvard University's psychologist, in a really systemic and complete manner, put forward the competency concept and promoted empirical research on competency. 
Some researchers have also targeted at competency of other groups of universities, such as teachers, college counselors and middle managers, but few theoretical researches focus on competency of university top officers, in particular to empirical researches. Marion ${ }^{[10]}$ studies the effective competency of vice chancellors in higher education by semi-structured interview. The interviewees are from 10 universities in the United Kingdom, and face to face interviews are performed.

The interview outline is amended to formal version according to prediction of three chancellors. The interviews include educational experience and work experience, highlights job position; a feature list is established, composed of attitudes, knowledge and behavior, by comparing with Great Eight Model by Bartram. The results also show competency in higher education is very different with other areas, but the academic governance and professional management are briefly discussed as two tendencies in Higher Education Management. Smith and Wolverton ${ }^{[1]]}$ (survey senior managers from NCAA Division I), and analyze their behavioral responses with factor analysis method. First, they make interviews to three different types of university senior managers (including sports executives, student affairs senior managers and academic affairs managers), basing on the diversity and cross-section of higher education management services, thus to find similarities and differences between the groups. Interview is divided into three parts: The first is to ask question related with demographic variables; the second is to learn about educational and vocational information and career-related experience; and the third is a statement of personal events and to propose some problems related with higher education leadership competency (HELC). According to the results of interviews and competency, the competency of university executives is divided into analytical, communication, student affairs, behavioral and external relations, total five dimensions. In addition, due to the unique political system and educational resource allocation system in America, some scholars have made research on community college. William ${ }^{[12]}$ takes Community College in Frederick as a research object, respectively interviews administrators, teachers and administrative staffs, and asks for them to rank different features by importance. Research is mainly based on competent leadership characteristics table developed by the American Association of Community Colleges (AACC). In addition to building a model, he also concludes that the characteristics of job description are not necessarily similar with others' evaluation (especially employees). Through the interview analysis on Community College and Chairman of the Council, Anthony ${ }^{[13]}$ verifies and optimizes six dimensions of the competency model by AACC. Kitty ${ }^{[14]}$ then interviews leaders from ulti-campus community college systems to verify and optimize the competency model by AACC. Through the interview material, he also proposes communication skills, financial management, procurement skills and knowledge are the critical quality and ability for these leaders.

Regarding competency of research-oriented universities chancellors in practices, existing researches are based on qualitative speculation and experience; or empirical investigation but in lack of representativeness, and they focus on different subjects, thus to fail to form a relatively uniform view; the existing research findings mostly focus on the university leadership qualities, conceptual level, with weak operability, and thus the findings are practically useless. It is necessary to consider how to determine quality and ability required for research-oriented universities chancellors, and apply to their selection, training and evaluation system, thus to promote competency theory's establishment and development and provide a new research perspective for solving these problems. If a scientific and rational competency theory is concluded to establish competency model of research-oriented universities chancellors (or senior management), it will not only provide basis and assessment tools for future leader selection, training and evaluation, and also can improve and enhance the comprehensive strength of university research management significantly.

\section{RESEARCH METHODS}

\section{Semi-structured Interviews}

This study adopts a stratified sampling method for sample selection in order to protect research comprehensiveness and representativeness. Firstly, BEI is adopted to set the corresponding standards for the interviewee. According to the process, interview is divided into preliminary interviews, formal interview, and supplementary interview.

In the preliminary interviews, 10 chancellors are selected, including five chancellors and five vice chancellors. The preliminary interviews are performed in Beijing, in order to further clarify the semi-structured interview outline. In the preliminary interviews, the key events are questioned from successful events, important events and difficult events. 
Totally 28 chancellors from universities in Beijing, Shanghai, Liaoning, Jilin, Hubei, Shandong and other provinces are selected as interviewees in formal interviews. The formal interview content contains four mandatory questions, the first one is based on individual characteristics: From your view, what is the most important task for university chancellors, please illustrate. The other three are themed at working behavior, including: Could you briefly summarize your working content and responsibilities? Please respectively illustrate the most successful and unsuccessful task among them.

Supplementary interview aims to make targeted interviews and propose supplementary questions after the formal interviews are completed. It also proposes confirmatory questions to any inadequate results arising from formal interviews. The original interviewee and new interviewees are available for supplementary interviews. Because of the rare nature of interviewees, it is available to integrate supplementary interview with formal interview, and answer supplemental questions according to answers content and status of interviewees, thus to ensure integrity of the information as obtained.

\section{Questionnaire and Revision}

The author amends competency codes basing on information obtained by semi-structured interviews, by using different encoding techniques; ranks them according to the frequency statistic data as mentioned in the problems, thus preliminarily concludes 107 competency behaviors. Face validity of the questionnaires is verified with expert opinion method in the questionnaire development process, which is discussed by 7 education department leaders, 4 relevant university chancellors, and 5 college middle managers, total 16 persons. After initial induction and integration, total 52 measurement items are obtained to interpret and confirm the contents, thus to avoid any ambiguity; finally, the official "competency model questionnaire for chancellors from research-oriented universities" is worked out.

\section{Regarding issuance of questionnaires}

The questionnaire survey is performed in 28 different research-oriented universities nation-wide, in the form of on-site filling-out under guidance. The questionnaire structure is divided into two parts: Background information and competencies. Background Information part includes gender, age, education level, job title, administrative duties, which is made in choice question. Competency part contains 52 questions, using Likert five-point scale method, one score for the least important and five scores for very important.

\section{Questionnaire collection}

496 questionnaires are collected, including 473 valid questionnaires, accounting for $95.2 \%$ of the total number. Half of collected questionnaires are used for exploratory factor analysis and the other are used for confirmatory factor analysis. Through rudimental statistics arrangement of the valid figures in the sample, deceptive statistical results can be derived from the survey [Table 1].

\section{Regarding the questionnaire reliability analysis}

Detection test is conducive to further testing the validity of measurement tools, excluding problematic or redundant measurement items as much as possible, minimizing interviewees' time in filling questionnaires, thus to improve the collection rate of the questionnaires. After the internal consistency test, the above questionnaire's

\begin{tabular}{|c|c|c|c|}
\hline Character & Category & Frequency & Percentage \\
\hline \multirow[t]{2}{*}{ Gender } & Male & 375 & 79.3 \\
\hline & Female & 98 & 20.7 \\
\hline \multirow[t]{7}{*}{ Age } & 56 years old and older & 32 & 6.8 \\
\hline & $51-55$ years old & 54 & 11.4 \\
\hline & $46-50$ years old & 106 & 22.4 \\
\hline & $41-45$ years old & 87 & 18.4 \\
\hline & $36-40$ years old & 85 & 18 \\
\hline & $31-35$ years old & 69 & 14.6 \\
\hline & Below the age of 30 & 40 & 8.5 \\
\hline \multirow{5}{*}{$\begin{array}{l}\text { Academic } \\
\text { background }\end{array}$} & Junior college & 2 & 0.4 \\
\hline & Undergraduate degree & 33 & 7 \\
\hline & Master degree & 137 & 29 \\
\hline & Doctoral degree & 295 & 62.4 \\
\hline & The other & 6 & 1.2 \\
\hline \multirow[t]{6}{*}{ Duty } & Teaching assistant & 17 & 3.6 \\
\hline & Lecturer & 70 & 14.8 \\
\hline & Associate professor & 89 & 18.8 \\
\hline & Professor & 224 & 47.4 \\
\hline & Academician & 2 & 0.4 \\
\hline & The other & 71 & 15 \\
\hline \multirow{4}{*}{$\begin{array}{l}\text { Administrative } \\
\text { capacity }\end{array}$} & Township capacity & 69 & 14.6 \\
\hline & Division capacity & 144 & 30.4 \\
\hline & University capacity & 43 & 9.1 \\
\hline & The other & 217 & 45.9 \\
\hline
\end{tabular}


inherent reliability itself is very ideal, and it has reached 0.926; the standardized coefficient is 0.929 to ensure the questionnaire reliability.

\section{Statistical Methods}

This study mainly adopts factor analysis, structural equation modeling and other statistical methods with statistical software SPSS20.0 and AMOS5.0; factor analysis is divided into exploratory factor analysis and confirmatory factor analysis. Thereinto, reliability analysis and factor analysis are performed with SPSS20.0, and confirmatory factor analysis is performed through AMOS5.0.

\section{Exploratory factor analysis}

It is available to further analyze structural elements of competency, thus to determine the different dimensions of university chancellors competency. In order to carry out exploratory factor analysis, KMO sampling adequacy test and Bartlett sphericity test are essential steps. Kaiser believes KMO's acceptable range is from 0.8 to 0.9 , the tested FMO is 0.916 , indicating that a lot of commonality factors exist among variables, and they are suitable for factor analysis. Bartlett sphericity test value is 0.000 , and it is statistically significant $(<0.001)$, meaning that there exist common factors in the correlation matrixes of parent groups, and they are suitable for factor analysis, as well as providing a basis for higher-order factor analysis.

Factor analysis assorts 44 items of the competence gauge into 8 factors after expunging irrelative items [Table 2].

According to the material substance, 8 factors are named. Factor 1 encompassing 9 items, involving work passion, benevolence, confidence, creative mindset, and responsibility, all of which are the traits of research-oriented chancellor, are named as personal traits; factor 2 encompassing 7 items, involving the followings such as familiarity with internal and external tendency of higher education and technology, grasp and attention to technology polices, all of which represent the chancellors' leadership, are dominated as leadership; factor 3 encompassing 9 items, involving wielding appreciation and grasp approaches, coordinating conflicts, all of which represent control competence, are named as control competence; factor 4 encompassing 4 items, including the competence of mindset, direction, investigation and ect, all of which are skills of chancellors, are esteemed as vocational skills; factor 5 encompassing 4 items, encompassing political stance, morality, and honor sense, all of which are the respect of emotions, so are
Table 2: Analytic results of principle component analysis of competence characteristics

\begin{tabular}{lcccccccc}
\hline Scale & \multicolumn{7}{c}{ Component } \\
\cline { 2 - 8 } & $\mathbf{1}$ & $\mathbf{2}$ & $\mathbf{3}$ & $\mathbf{4}$ & $\mathbf{5}$ & $\mathbf{6}$ & $\mathbf{7}$ & $\mathbf{8}$ \\
\hline T40 & 0.759 & & & & & & & \\
T42 & 0.757 & & & & & & & \\
T43 & 0.735 & & & & & & & \\
T39 & 0.698 & & & & & & & \\
T44 & 0.687 & & & & & & & \\
T38 & 0.634 & & & & & & & \\
T36 & 0.631 & & & & & & & \\
T37 & 0.596 & & & & & & & \\
T41 & 0.493 & & & & & & & \\
T7 & & 0.641 & & & & & & \\
T13 & & 0.631 & & & & & & \\
T14 & & 0.622 & & & & & & \\
T26 & & 0.496 & & & & & & \\
T6 & & 0.491 & & & & & & \\
T12 & & 0.484 & & & & & & \\
T5 & & 0.439 & & & & & &
\end{tabular}

T31 0.563

T34 0.556

$\mathrm{T} 17 \quad 0.548$

T29 0.537

T30 0.526

T33 0.490

T25 0.476

T16 $\quad 0.470$

T35 0.440

$\begin{array}{ll}\text { T9 } & 0.755\end{array}$

T8 0.712

T10 $\quad 0.661$

$\mathrm{T} 11$

$\begin{array}{ll}\mathrm{T} 1 & 0.779\end{array}$

$\begin{array}{ll}\mathrm{T} 4 & 0.752\end{array}$

T3 0.713

T2 0.686

$\begin{array}{ll}\mathrm{T} 24 & 0.827\end{array}$

$\begin{array}{ll}\mathrm{T} 23 & 0.797\end{array}$

$\begin{array}{ll}\mathrm{T} 15 & 0.741\end{array}$

T22 0.337

$\begin{array}{ll}\text { T20 } & 0.760\end{array}$

$\begin{array}{ll}\mathrm{T} 21 & 0.683\end{array}$

$\begin{array}{ll}\mathrm{T} 19 & 0.657\end{array}$

$\begin{array}{ll}\mathrm{T} 18 & 0.497\end{array}$

$\begin{array}{ll}\text { T28 } & 0.777\end{array}$

$\begin{array}{ll}\mathrm{T} 27 & 0.718\end{array}$

T32 0.408

named as vocational emotion; factor 6 encompassing 4 items, encompassing scientific management, academic level and ect, are named as vocational knowledge; factor 7 encompassing 4 items, encompassing the substance such 
Table 3: Competency model of chancellor in research-oriented universities

\section{Personal traits}

Decision behavior

Control competence

Organizing behavior

Vocational emotions

Vocational skills

Vocational knowledge

Leadership

as introduction of talents and team construction, all of which represent the organizing behaviors, and thus are named as organizing behaviors; factor 8 encompassing 3 items, encompassing empowerment, option and nurturing of talents, all of these represent decision behavior and are named as this.

Standard load coefficient are composed of vocational emotions, which can be successively dividend into responsibility (0.779), morality (0.752), and honor sense (0.713); personal traits which can be successively dividend into passion (0.759), confidence (0.757), bigotry (0.735), and dedication (0.698); vocational knowledge which can be successively dividend into scientific management (0.827), higher education (0.797), a certain academic field (0.741), some certain academic fields (0.698); vocational skills which can be successively dividend into politic comprehension (0.755), execution (0.712), organize (0.661), decision (0.640), academic influence (0.588), communication (0.574); decision behavior which can be successively dividend into democratic decision (0.760), independent decision (0.683); leadership, which can be successively dividend into award (0.642), punishment (0.631), wielding of award and punishment (0.622), communication (0.496), confliction arrangement (0.491), consulting (0.484), empowerment (0.439), centralization and decentralization of power (0.408); organizing behavior which can be successively dividend into police (0.777), team construction (0.718), experience (0.408); control competence, which can be successively dividend into treatment of emergence (0.563), strict assessment (0.548), loop scientific assessment (0.562). 8 dimensions of the 33 factors can explain 59.825\% to the competence of chancellor [Table 3].

\section{Model checking}

Exploratory factor analysis is used for exploring unknown world, but only stable results of exploratory factor analysis must be widely applicable. Therefore, further studies need to apply additional samples for confirmatory factor analysis, basing on exploratory factor analysis results, thus to test the reasonableness of factor structure. ${ }^{[15]}$ In this study, the AMOS5.0 software is sued for testing factor structure.

\section{First-order Model Checking}

Confirmatory factors are analyzed with the other half of samples; the fitting degree is mainly based on three categories of fitting indexes, namely, absolute index, relative index and simple index. Absolute index is a statistic result by comparing theoretical model and saturated model, and the commonly used index is $x^{2} / d f$, RM-SEA, and GFI. RM-SEA is unaffected by sample size, and thus it is regarded as a good absolute fit index; GFI is considered as biased from overall estimate of asymptotic value (Mcdonald and Marsh, 1990). ${ }^{[16]}$ It is generally considered the acceptable range of $\mathrm{x}^{2} / \mathrm{df}$ is from 2.0 to 5.0, the approximation value of root mean square error is as follows: RM-SEA $<0.1$, the goodness of fit GFI is more than 0.9. In this study, the measured $\mathrm{x}^{2} / \mathrm{df}$ is 2.03 , RM-SEA value is 0.082 , GFI is 0.903 , indicating that the theoretical model fits better with the sample data. Relative fit index is a statistic result by comparing theoretical model and reference model and the commonly used indexes include comparative fit index (CFI), normed fit index (NFI), non-normed fit index (NNFI), incremental fit index (IFI) and so on the measured CFI, NFI, NNFI, IFI are respectively 0.929, 0.87, $0.90,0.919$. All fit indices are within a predetermined range, and the model is acceptable. Simple fit index is derived from the previous two types of indices, and aim to punish models containing many parameters, commonly expressed with PNFI. The measured PNFI is 0.702.

\section{Second-order Model}

Confirmatory factor analysis provides meaningful testing and fitting for the hypothetical model. Compared with the exploratory factor analysis, confirmatory factor analysis allows researchers to integrate theory and measurement closely on the basis of relevant theories, through specific limitations. Second-order model fitting aims to further confirm rationality of five dimensions under university chancellor competency. It is available to sample second-order factors from the competency model. Due to poor change in Chi-square value as decreased with the degree of freedom, second-order model should fit better. It is showed that the five dimensions of university chancellor competency can be integrated to the same factor in a 
higher order, indicating university chancellors competency model fits well with the actual observed data model. Personal traits (0.85), decision behavior (0.90), control competence $(0.90)$, organizing behavior $(0.94)$, vocational emotions (0.87), vocational skills (0.93), vocational knowledge (0.87), leadership (0.86), all the 8 factors can further represent competence of chancellors. Among them, organizing behavior and vocational skills are most important, which demonstrate that the competence are mostly reflected in talents introduction, team conduction and mindset, decision and investigation, conforming to common sense.

\section{CONCLUSIONS AND DISCUSSION}

As the Chinese education industry is being internationalized, a lot of relevant theoretical and practical guidance are urgently needed for revealing competency structural model of Chinese university chancellors and measurement tools, thus providing an important complement for existing theory. Establishment of competency model for Chinese university chancellors is theoretically and practically significant to management of Chinese colleges and universities. How to build a scientific, rational, and practical competency model of university chancellors is very essential to the selection and training of university chancellors.

The research aims to explore competency of university chancellors in China. Through empirical multi-method oriented research model, with exploratory factor analysis and confirmatory factor analysis, four dimensions of 10 competency features for university chancellor competency are concluded in the paper. starting from the typical ideological and political qualities in university chancellors, the paper makes in-depth analysis on the competency model and hierarchical structure of university chancellors, further reveals the external behavior characteristics and potential features of outstanding chancellors, thus laying a scientific foundation for competency development and management of domestic university chancellors, also making useful exploration for professionalization process of university chancellors. In future studies, the specific content of "professionalized management" will be further integrated into selection, appointment, management, supervision, examination and evaluation of university chancellors, thus providing quantitative standards and assessment tools for professionalized management on chancellors in charge of scientific research in Chinese research-oriented universities.

\section{REFERENCES}

1. Zhao YY. Management of the university is doing major research projects. 2011. http://www.edu.takungpao.com/ksjy/ $\mathrm{gk} / \mathrm{q} / 2014 / 0428 / 2445668 . \mathrm{html}$. [Retrieved on 2014 Oct 30].

2. Gu YC. President competency theory analysis of the modern university. Forum Contemp Educ 2007;1:33-4.

3. Jia JL. President ability constituent elements analysis of the modern university. Forum Contemp Educ 2007;3:15-7.

4. Ma L. Research to the influential factors of the current principal's competence between Chinese and American research universities. High Educ Res Eval 2009;4:19-21.

5. Yin XM. Dual-core competency model research of $t$ of high-level managers in university. Mod Educ Manage 2009;10:73-5.

6. Li B. The study on competency model of high-level managers in university. Wuhan: Wuhan University of Technology; 2008.

7. Ma LH. An exploratory analysis of leadership system building of university presidents. J Natl Acad Educ Adm 2010;11:14-20.

8. Liu JY, Lou CW, Ren YY. A study on the competency model for university presidents. Mod Univ Educ 2010;4:40-4.

9. The Special Subject Study Group. A study on the model of the characteristics of the competency of the leaders of China's Universities and Colleges. Manage World 2010;6:74-82.

10. Marion S. Competencies for effective leadership in higher education. Int J Educ Manage 2007;21:407-17.

11. Smith ZA, Wolverton M. Higher education leadership competencies: Quantitatively refining a qualitative model. J Leadersh Organ Stud 2010;21:61-70.

12. William HR. A Case Study of American Association of Community College Leadership Characteristics. Fairfax: George Mason University; 2007.

13. Anthony $\mathrm{MH}$. The Competencies for Community College Leaders: Community College Presidents' and Trustee Board Chairpersons' Perspectives. Tampa Bay: University of South Florida; 2008.

14. Kitty SC. Leadership competencies of branch campus administrators in multi-campus community college systems. Ames: Lowa State University; 2009.

15. Hou JT, Cheng ZJ. Application and analytical strategies of structural equation modeling. Psychol Explor 1999;1:63-5.

16. Mcdonald RP, Marsh HW. Choosing a multivariate model noncent rality and goodness of fit. Pychol Bull 1990;2:247-55.

How to cite this article: Hu W, Ding K, Gu L, Qu Z. Research on the competency model of chancellors in charge of scientific research in Chinese research-oriented universities. J Sci Res 2014;3:104-10.

Source of Support: Nil, Conflict of Interest: None declared 